\title{
A virtual hydrological framework for evaluation of stochastic rainfall models
}

\author{
Bree Bennett ${ }^{1}$, Mark Thyer ${ }^{1}$, Michael Leonard ${ }^{1}$, Martin Lambert ${ }^{1}$, and Bryson Bates ${ }^{2}$ \\ ${ }^{1}$ School of Civil, Environmental and Mining Engineering, University of Adelaide, \\ North Terrace Campus, 5005, South Australia, Australia \\ ${ }^{2}$ School of Agriculture and Environment, The University of Western Australia, Crawley, 6009, Western Australia, Australia
}

Correspondence: Bree Bennett (bree.bennett@adelaide.edu.au)

Received: 13 September 2018 - Discussion started: 25 September 2018

Revised: 21 September 2019 - Accepted: 1 October 2019 - Published: 25 November 2019

\begin{abstract}
Stochastic rainfall modelling is a commonly used technique for evaluating the impact of flooding, drought, or climate change in a catchment. While considerable attention has been given to the development of stochastic rainfall models (SRMs), significantly less attention has been paid to developing methods to evaluate their performance. Typical evaluation methods employ a wide range of rainfall statistics. However, they give limited understanding about which rainfall statistical characteristics are most important for reliable streamflow prediction. To address this issue a formal evaluation framework is introduced, with three key features: (i) streamflow-based, to give a direct evaluation of modelled streamflow performance, (ii) virtual, to avoid the issue of confounding errors in hydrological models or data, and (iii) targeted, to isolate the source of errors according to specific sites and seasons. The virtual hydrological evaluation framework uses two types of tests, integrated tests and unit tests, to attribute deficiencies that impact on streamflow to their original source in the SRM according to site and season. The framework is applied to a case study of 22 sites in South Australia with a strong seasonal cycle. In this case study, the framework demonstrated the surprising result that apparently "good" modelled rainfall can produce "poor" streamflow predictions, whilst "poor" modelled rainfall may lead to "good" streamflow predictions. This is due to the representation of highly seasonal catchment processes within the hydrological model that can dampen or amplify rainfall errors when converted to streamflow. The framework identified the importance of rainfall in the "wetting-up" months (months where the rainfall is high but streamflow low) of the annual hydrologic cycle (May and June in this case study) for providing
\end{abstract}

reliable predictions of streamflow over the entire year despite their low monthly flow volume. This insight would not have been found using existing methods and highlights the importance of the virtual hydrological evaluation framework for SRM evaluation.

\section{Introduction}

Stochastic rainfall model (SRM) simulations are used primarily as inputs to a hydrological model, for simulating realisations of streamflow. Streamflow simulations are then used to assess hydrological risks, such as floods (e.g. Camici et al., 2011; Li et al., 2016) or droughts (e.g. Henley et al., 2013; Mortazavi-Naeini et al., 2015; Paton et al., 2013). When evaluating the efficacy of SRMs, current approaches that make comparisons to observed rainfall or streamflow have limited diagnostic ability. They are unable to make a targeted evaluation of the SRM's ability to reproduce streamflow characteristics of practical interest. This paper introduces a new virtual framework that enables targeted hydrological evaluation of SRMs.

Observed-rainfall evaluation is the most common method for SRM evaluation (Baxevani and Lennartsson, 2015; Bennett et al., 2018; Evin et al., 2018; Rasmussen, 2013; Srikanthan and Pegram, 2009; Wilks, 2008). As shown in Fig. 1a, it involves comparisons between observed and simulated rainfall typically using a large number of evaluation statistics. Often, this method shows "mixed" performance where many statistics are reproduced well but some are poor. While these assessments are useful, a drawback is that it is difficult to 
(a) Observed-rainfall evaluation

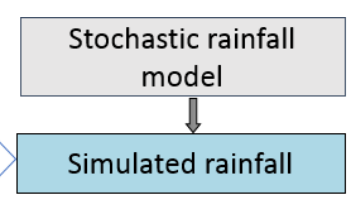

(b) Observed-streamflow evaluation

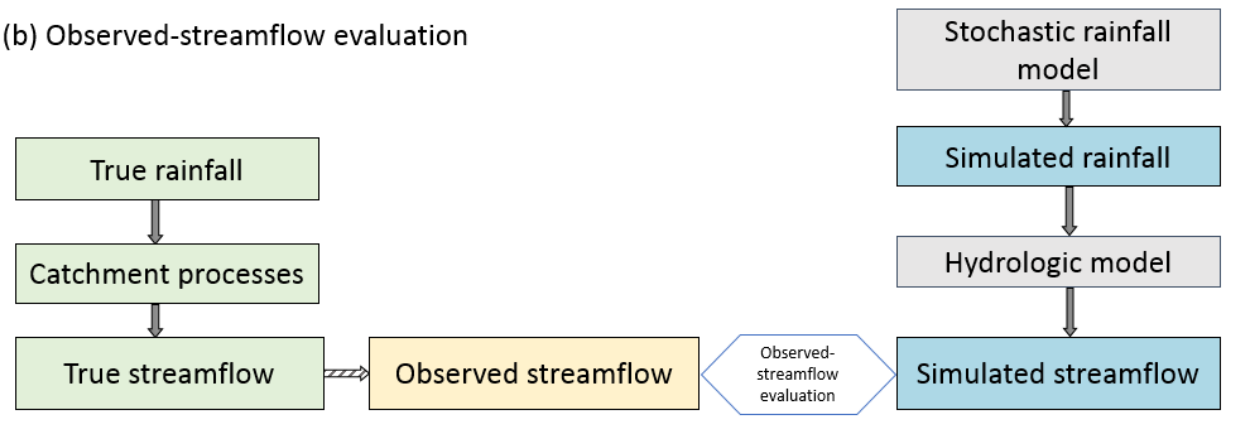

(c) Virtual hydrological evaluation

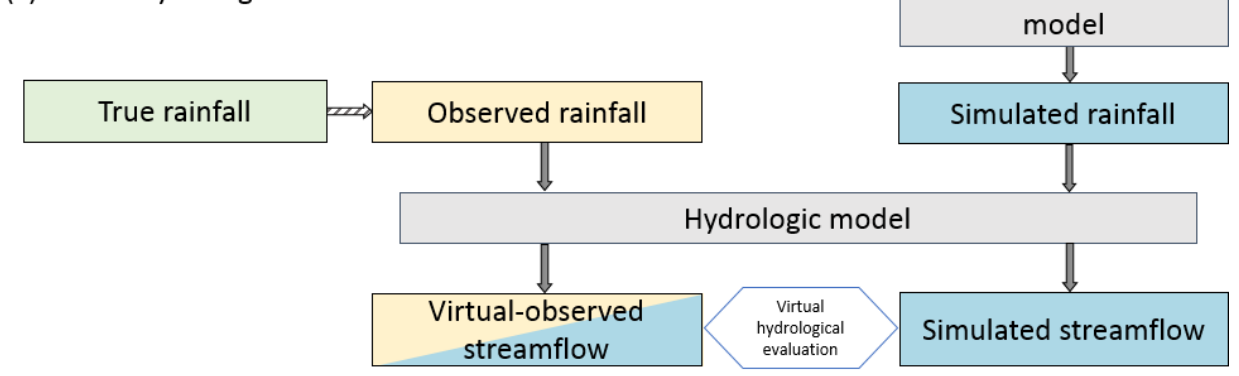

\begin{tabular}{|ll}
\hline Key \\
\end{tabular} Observed $\square$ Simulated $\square$ True $\square$ Virtual-observed $\square$ Model

Figure 1. Schematic of (a) observed-rainfall evaluation where simulated rainfall is compared against observed rainfall and (b) observedstreamflow evaluation where simulated streamflow is compared against observed streamflow. (c) Virtual hydrological evaluation framework where simulated streamflow is compared against virtual-observed streamflow.

ascertain whether the SRM's performance is sufficient in terms of predictions of practical interest, which are typically streamflow-based. This means it is unclear whether it is necessary to invest time and effort to address instances of poor performance, when the majority of statistics are well reproduced (Bennett et al., 2018; Evin et al., 2018).

To overcome limitations in observed-rainfall evaluation methods, the conventional alternative is to evaluate the rainfall model's performance in terms of streamflow (e.g. Blazkova and Beven, 2002, 2009; Camici et al., 2011; McMillan and Brasington, 2008) and is referred to as "observed-streamflow evaluation". From Fig. 1b, observedstreamflow evaluation typically involves (1) a SRM that produces simulations of rainfall that are (2) input to a hydrological model to produce simulated streamflow, which is (3) con- verted to the predictions of interest (e.g. the flood frequency distribution) and (4) compared against the observed streamflow predictions of interest. A challenge with observedstreamflow evaluation is that when there is poor predictive performance (i.e. a significant discrepancy between the observed and predicted streamflow), it is difficult to ascertain whether the poor performance was caused by the hydrological model or the SRM. Hydrological model predictive performance can vary substantially from catchment to catchment due to data errors (rainfall or streamflow) and model structural errors (Andreassian et al., 2001; Coxon et al., 2015; Evin et al., 2014; Kuczera and Williams, 1992; McInerney et al., 2017; Renard et al., 2011), which makes it difficult to evaluate the performance of the SRM and identify opportunities for improvement. 
Table 1. Comparison of the sources of error for observed-rainfall, observed-streamflow and virtual hydrological evaluation frameworks as well as whether the evaluation is streamflow-based.

\begin{tabular}{|c|c|c|c|c|}
\hline & \multicolumn{3}{|c|}{ Source of error } & \multirow[b]{2}{*}{$\begin{array}{l}\text { Streamflow-basec } \\
\text { evaluation }\end{array}$} \\
\hline & $\begin{array}{l}\text { Stochastic rainfall } \\
\text { model }\end{array}$ & $\begin{array}{l}\text { Hydrological } \\
\text { model }\end{array}$ & $\begin{array}{l}\text { Observed } \\
\text { streamflow }\end{array}$ & \\
\hline Observed-rainfall evaluation & Yes & No & No & No \\
\hline Observed-streamflow evaluation & Yes & Yes & Yes & Yes \\
\hline Virtual hydrological evaluation & Yes & No & No & Yes \\
\hline
\end{tabular}

The focus of this paper is the development and application of a virtual hydrological evaluation framework for streamflow-based evaluation of SRMs. As shown in Fig. 1c, a virtual hydrological evaluation involves the comparison of simulated streamflow statistics (produced by the hydrological model by inputting simulated rainfall from a SRM) against virtual-observed streamflow statistics (produced by the hydrological model by inputting observed rainfall). This framework is designed to focus on streamflow predictions of interest, similar to observed-streamflow evaluation, but to reduce the sources of error to only those introduced by the SRM. To illustrate this, Table 1 gives an overview of the sources of error for the three evaluation frameworks and indicates whether the evaluations are streamflow-based. The observed-rainfall evaluation framework is used to identify errors in the SRM, but is not able to determine their implications for streamflow. The observed-streamflow framework provides an absolute measure of performance, since ultimately the goal is to match streamflow observations or statistics. However, with this approach it is not possible to readily identify whether discrepancies in the simulated streamflow are attributed to the SRM, the streamflow observations, or poor process representation within the hydrological model. In contrast, the virtual hydrological evaluation framework is a relative measure of performance, where the hydrological model is a common factor in the production of simulated streamflow and virtual-observed streamflow that is used as a baseline for comparison. By using a virtual baseline, observed streamflow is not directly required in the evaluation as both simulated and observed rainfall undergo transformation by the same process representation (i.e. the hydrological model). This enables discrepancies in the streamflow to be identified in terms of features of the SRM.

To date, "virtual experiments", that is, experiments that focus on comparisons between streamflow simulated under different conditions or inputs (i.e. virtual streamflow) without relying on comparisons to observed streamflow, have been used in a variety of contexts. Examples include (i) the evaluation of hydrological model sensitivity (e.g. Ball, 1994; Nicótina et al., 2008; Paschalis et al., 2013; Shah et al., 1996; Wilson et al., 1979), including the identification of rainfall features of interest in terms of hydrological behaviour (e.g. Sikorska et al., 2018), (ii) the development of new techniques for flood frequency analysis (e.g. Li et al., 2014, 2016), and (iii) the calibration, validation, and selection of SRMs (e.g. Kim and Olivera, 2011; Müller and Haberlandt, 2018).

The framework presented in this paper is a significant advance from previously reported virtual experiments because it presents a formal framework to identify key deficiencies in the SRM by (1) extending the comprehensive and systematic evaluation (CASE) framework (developed by Bennett et al., 2018, for observed-rainfall evaluation and used by Evin et al., 2018, and Khedhaouiria et al., 2018) that systematically categorises performance at multiple spatial and temporal scales using quantitative criteria for each statistic for use in virtual hydrological evaluations and (2) utilising two types of virtual experiments that are able to identify the source of key deficiencies in the SRM at specific locations and time periods.

The key objectives of this paper are the following.

1. Introduce a formalised framework for the virtual hydrological evaluation of SRMs: the new framework is a stepwise procedure that enables the identification of poor performing sites, then poor performing time periods, and then the key deficiencies in the SRM for those sites and time periods by drawing on the systematic application of quantitative performance criteria.

2. Present two different tests which are part of the framework: the integrated test and a new type of test, the unit test. Combined use of these tests allows streamflow discrepancies to be attributed to their original source in the SRM according to site and season.

3. Demonstrate the framework on a daily SRM at multiple sites to evaluate performance at daily, monthly, and annual timescales and to contrast the outcomes with conventional evaluation methods.

The virtual hydrological evaluation framework is explained in Sect. 2 with the procedures for the integrated test and unit test outlined in Sects. 2.2.2 and 2.4.1. Daily SRMs have been developed for 22 sites in the Onkaparinga catchment, South Australia (Sect. 3), and are used to illustrate the procedure (Sect. 4). Discussion and conclusions emphasise the features of the framework and the different recommendations it can identify for improving the SRM (Sects. 5 and 6). 


\section{Virtual hydrological evaluation framework}

\subsection{Overview}

A virtual hydrological evaluation involves the comparison of simulated streamflow statistics to virtual-observed streamflow statistics (Fig. 1c), defined as the following.

- Simulated streamflow is streamflow produced by the hydrological model by inputting simulated rainfall at a given site.

- Virtual-observed streamflow is streamflow produced by the hydrological model by inputting observed rainfall at the same given site.

The virtual framework undertakes a relative assessment of the simulated and observed rainfall after its transformation by the same hydrological model to provide insight into the performance of the SRM. Because the hydrological evaluation is a relative comparison of the observed and simulated rainfall, it is important that all other model parameters and extraneous variables (e.g. potential evapotranspiration) relating to the hydrological model are kept the same for the simulation of both virtual-observed and simulated streamflow. It is also important that the selected hydrological model is fit for purpose so that it can simulate the streamflow characteristics of interest. This selection process should also ensure that the hydrological model is compatible with the tested rainfall model and the objectives of the test (i.e. a distributed hydrological model would not be selected to evaluate a single-site rainfall model for deficiencies).

The virtual hydrological evaluation framework is best used to augment and complement existing evaluation methods, rather than act as a replacement. The three evaluation frameworks could work together as follows, where (i) observedrainfall evaluation identifies any deficiencies in the SRM prior to any hydrological considerations; (ii) the virtual hydrological framework identifies which of these rainfall deficiencies impact on the key predictions of interest, that is, simulated streamflow; and (iii) observed-streamflow evaluation provides a final validation. Therefore, together they enable a more focused approach to identify opportunities for improvement of a SRM. This is because the ultimate goal of the SRM modelling process remains the same: to match observed streamflow for a catchment of interest.

The formal implementation of the virtual hydrological evaluation framework is summarised in Fig. 2. It uses a series of steps to identify poor performing sites (i.e. specific locations in space, for example, the location of a rainfall gauge), then poor performing time periods, and then key deficiencies in the SRM for those sites and time periods. It combines both observed rainfall-evaluation and virtual hydrological evaluation. The virtual hydrological evaluation includes two different types of tests, an "integrated test" that isolates issues for a given site and "unit tests" that isolate issues for specific time periods. This enables the diagnosis of the key deficiencies in the simulated rainfall. The following sections explain the three steps in turn.

\subsection{Step 1 - identify poor performing sites}

The first step focuses on using integrated tests to identify poor performing sites for further evaluation. Following the selection of a primary streamflow characteristic of interest and a suitable hydrological model, integrated tests are conducted for each rainfall site (described below in Sect. 2.2.2). The results of the integrated tests are then used to identify sites that are poor performing, according to the systematic application of quantitative performance criteria (see Sect. 2.2.3), for the primary streamflow characteristic.

\subsubsection{Selection of the primary streamflow characteristic and relevant hydrological model}

In order to undertake an integrated test, an appropriate hydrological model is required to simulate the streamflow. The hydrological model should be selected on the basis that it is capable of simulating streamflow for the timescales, magnitudes, and physical processes of interest to the intended application. For example, a capability for simulating flow volumes is important for yield. A streamflow characteristic of interest, herein termed the "primary streamflow characteristic", is then selected to enable a method for filtering sites and concentrating the investigation of the SRM on sites that perform poorly in terms of its intended application. For example, the distribution of annual total flow would be a suitable characteristic when investigating yield. Following the identification of the hydrological model and primary streamflow characteristic, an integrated test is conducted for each rainfall site, which serves as an overall test of the SRM's performance.

\subsubsection{Integrated test procedure}

The integrated test proceeds for a single site by transforming the time series of observed and simulated rainfall, via the hydrological model (Fig. 1c). Consider the time series of observed daily rainfall, $R^{\text {obs }}$, for each year at a given site. This rainfall time series is transformed according to a hydrological model $g$ [] to produce the virtual-observed streamflow, denoted as $Q^{\mathrm{vo}}$, and “..." are additional inputs (e.g. potential evapotranspiration).

$Q^{\mathrm{vo}}=g\left[R^{\mathrm{obs}}, \ldots\right]$

Likewise, all replicates of the simulated daily rainfall, $R^{\mathrm{sim}}$, for each year at a given site are transformed according to the hydrological model $g$ [] to produce simulated streamflow replicates, $Q^{\text {sim }}$.

$Q^{\text {sim }}=g\left[R^{\text {sim }}, \ldots\right]$ 


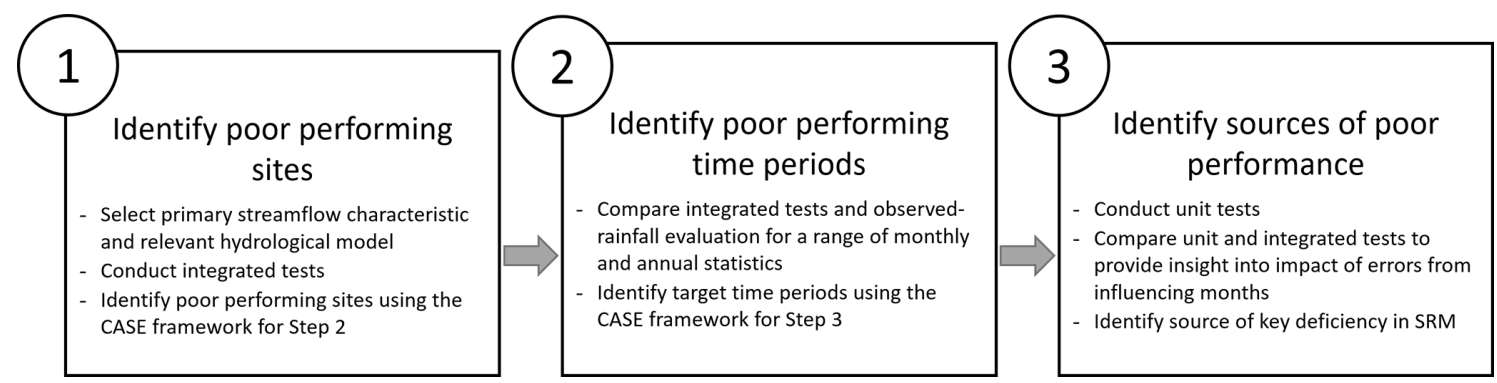

Figure 2. Virtual hydrological evaluation procedure.

If there is a discrepancy between the simulated streamflow, $Q^{\text {sim }}$, and virtual-observed streamflow, $Q^{\text {vo }}$, distributions, this indicates that there is a deficiency in the simulated rainfall for that site.

The integrated test procedure is explained in terms of daily rainfall and daily streamflow at a single site, as it is herein applied to evaluate a daily rainfall model (see Sect. 3). This test procedure can be extended to other timescales and spatial scales (e.g. spatial rainfall, subdaily rainfall). These extensions are discussed in Sect. 5.4.

\subsubsection{Identify poor performing sites using the CASE framework}

The integrated test results aim to identify the sites that are poor performing for the primary streamflow characteristic. Model performance is categorised using a CASE framework approach as "good", "fair", or "poor" following Bennett et al. (2018). The quantitative tests for each performance category are provided in Table 2 alongside an illustration of each in Fig. 3. The quantitative tests proceed by comparing the statistics of the virtual-observed streamflow against those calculated from replicates of the simulated streamflow. Performance was categorised as "good" if the selected statistic for the virtual-observed streamflow fell within the $90 \%$ limits of the statistic calculated from the simulated streamflow replicates (Fig. 3, case i), as "fair" if the virtual-observed statistic fell outside the $90 \%$ limits of the simulated streamflow replicates but within the $99.7 \%$ limits (Fig. 3, case ii), and as "poor" if otherwise (Fig. 3, case iii).

\subsection{Step 2 - identify poor performing time periods}

The second framework step is to identify poor performing time periods by conducting a detailed analysis of the integrated test results and comparing these results with an observed-rainfall evaluation at the monthly scale.

Evaluating monthly total flows is a valuable test of SRM performance as the production of monthly total flow volumes relies on the integration of many daily rainfall characteristics (amount, duration, persistence). For each of the poor performing sites, each of these statistics for each month are categorised as "good", "fair", and "poor" using the CASE

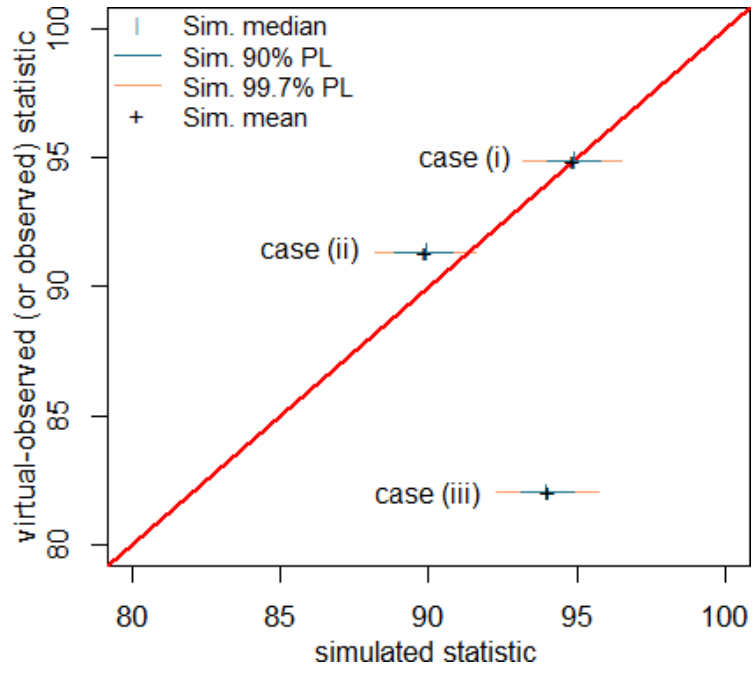

Figure 3. Illustration of performance classification: case (i) shows "good" performance, case (ii) shows "fair" performance, and case (iii) shows "poor" performance. Adapted from Bennett et al. (2018).

framework. See Sect. 2.2.3 for further explanation of the categorisation procedure. This enables the identification of poor performing time periods from the perspective of the virtual hydrological evaluation.

Poor performance in reproducing virtual-observed streamflow is then contrasted against an observed-rainfall evaluation so that specific poor performing time periods can be identified for further investigation in Step 3. By contrasting CASE performance categories ("good", "fair", and "poor") for observed-rainfall evaluation against virtualobserved streamflow evaluation, poor performing time periods from both rainfall and streamflow perspectives can be identified. This comparison between the observed-rainfall evaluation and the virtual hydrological evaluation (integrated test) can be summarised graphically (e.g. see Fig. 7, Sect. 4.2). 
Table 2. CASE performance classification criteria. Adapted from Bennett et al. (2018).

\begin{tabular}{lll}
\hline $\begin{array}{l}\text { Performance } \\
\text { classification }\end{array}$ & Test & Key \\
\hline "good" & Observation lies within the $90 \%$ limits (case i) & $\square$ \\
"fair" & Observation lies outside the $90 \%$ limits but within the $99.7 \%$ limits (case ii) & $\square$ \\
"poor" & Otherwise (case iii) & \\
\hline
\end{tabular}

\subsection{Step 3 - identify sources of poor performance}

The third step of the framework is to identify sources of poor performance in streamflow according to deficiencies in the simulated rainfall. Step 2 identifies the poor performing time periods from a streamflow perspective. However, due to catchment "memory", the poor performance in streamflow could be due to deficiencies in the simulated rainfall from a range of potential influencing months during or prior to the poor performing time period. For example, poor streamflow performance in an evaluated month may be due to the influence of (i) rainfall deficiencies mostly in the same month (i.e. concurrent influencing months), (ii) rainfall deficiencies over a contiguous block of months including and preceding the evaluated month (i.e. prior and concurrent influencing months), or (iii) rainfall deficiencies in a preceding month more so than in the evaluated month (i.e. prior influencing months). The integrated test cannot isolate which influencing months produce these deficiencies. Therefore, the unit test is designed to enable the identification of sources of poor performance in streamflow. The sources of poor performance are described in terms of which influencing months exhibit key deficiencies in simulated rainfall and therefore which SRM components should be improved.

\subsubsection{Unit test procedure}

The unit test investigates the impact of simulated rainfall in a given influencing month on the production of streamflow in an evaluated month of interest. This is achieved by splicing observed and simulated rainfall into a single time series which is used to produce simulated streamflow.

Following Fig. 4a, consider the time series of observed, $R^{\text {obs }}$, and simulated, $R^{\text {sim }}$, daily rainfall for each year (and replicate) at a given site. Figure 4a illustrates the embedding of simulated rainfall $R_{k}^{\text {sim }}$ in an influencing month, $k$, within observed rainfall $R_{m}^{\text {obs }}$ for all other months $m \in$ $\{1, \ldots, 12 \mid m \neq k\}$. The resulting spliced rainfall time series $R_{(k)}^{\text {spl }}$ is denoted with respect to the influencing month, $k$, and has the same length as the corresponding observed, $R^{\text {obs }}$, and simulated, $R^{\text {sim }}$, time series.

$$
R_{(k)}^{\mathrm{spl}}=\bigcup_{m=1}^{12} \begin{cases}R_{m}^{\mathrm{sim}} ; & m=k \\ R_{m}^{\mathrm{obs}} ; & m \neq k\end{cases}
$$

For example, if June $(k=6)$ is selected as the influencing month, each year of the spliced time series, $R_{(6)}^{\mathrm{spl}}$, would be composed as follows:

$R_{(6)}^{\mathrm{spl}}=\left\{R_{1}^{\mathrm{obs}}, \ldots, R_{5}^{\mathrm{obs}}, R_{6}^{\mathrm{sim}}, R_{7}^{\mathrm{obs}}, \ldots, R_{12}^{\mathrm{obs}}\right\}$.

The ensemble of $k=1, \ldots, 12$ spliced rainfall time series $R_{(k)}^{\mathrm{spl}}$ for all influencing months and additional inputs (e.g. potential evapotranspiration) indicated by “..." is transformed according to a hydrological model $g$ [] to produce an ensemble of simulated streamflow, $Q_{(k)}^{\mathrm{spl}}$. This procedure is repeated for all simulated rainfall replicates.

$Q_{(k)}^{\mathrm{spl}}=g\left[R_{(k)}^{\mathrm{spl}}, \ldots\right]$

By construction, the spliced rainfall is identical to the observed rainfall for all months other than the influencing month, so any errors in streamflow statistics can be attributed to the influencing month free from other factors.

The full set of spliced rainfall (e.g. spliced rainfall for each month designated as the influencing month $R_{(k)}^{\mathrm{spl}} ; k=$ $1, \ldots, 12)$ is input to the hydrological model. This step is repeated for all available replicates of the spliced time series. The results of the unit test and the integrated test (Steps 1-2) are then investigated and compared by selecting each month as the evaluated time period in turn as well as other key time periods (e.g. annual).

\subsubsection{Compare unit tests and integrated tests}

Side-by-side comparison of the results of the integrated test and unit tests are given in terms of the errors for selected monthly and annual statistics (see the illustration in Fig. 4b). The comparison of errors from the unit test forms the basis of interpretation for hydrological insights and their relationship with the SRM.

A relative error metric, \%Err, is used to enable a comparison between the virtual-observed streamflow and the evaluated streamflow replicates from the integrated or unit tests ( $Q^{\mathrm{sim}}$ or $Q_{(k)}^{\mathrm{spl}}$ ) for time periods of interest (e.g. annual level or particular season or month). In this way the targeted hydrological evaluation centres on a specific subset of streamflows relating to the evaluated time period, $t$. In this paper, examples are provided for evaluated time periods at the monthly and annual scales. 
(a) Unit and integrated testing procedure

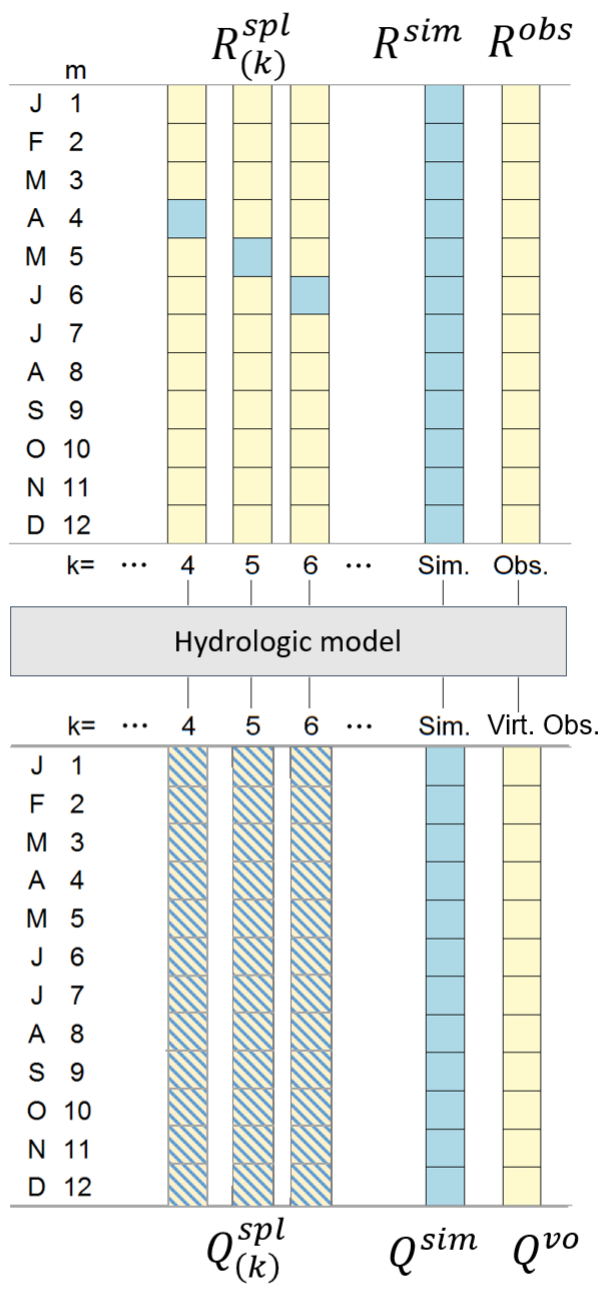

(b) Error profile for unit and integrated tests

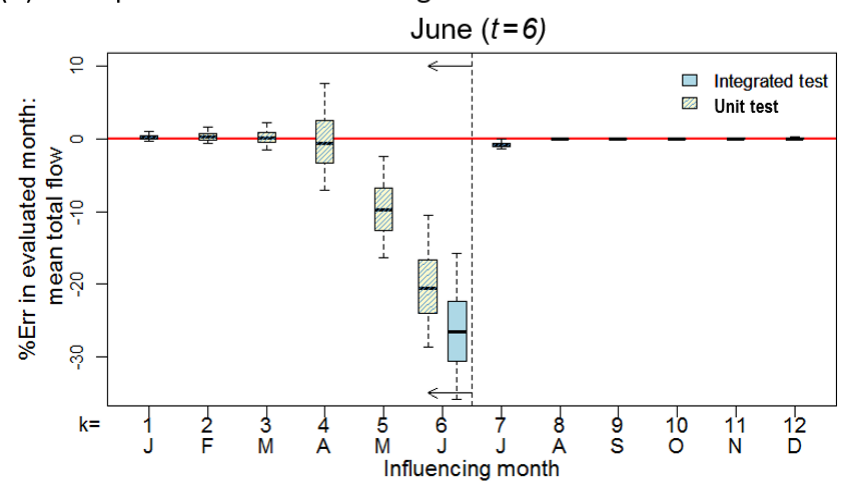

Figure 4. Schematic of (a) the method of constructing a unit test by embedding simulated months in an observed time series and (b) the error profile produced when using the integrated and unit tests for the evaluated time period of June $(t=6)$ (boxplot whiskers indicate the $90 \%$ limits of the simulated streamflow replicates). For the unit test the errors in the evaluated period $(t)$ are calculated as the difference between $Q_{(k)}^{\mathrm{spl}}$ and $Q_{(t)}^{\mathrm{vo}}$. For the integrated test the errors are calculated as the difference between $Q^{\text {sim }}$ and $Q_{(t)}^{\text {vo }}$.
Using the function $h[]$ to denote a calculated statistic of interest (e.g. mean or standard deviation), the relative error in an evaluated time period $t$ (e.g. annual or particular month) is given by

$\% \operatorname{Err}_{(t)}=\frac{h\left[Q_{(t)}^{\mathrm{eval}}\right]-h\left[Q_{(t)}^{\mathrm{vo}}\right]}{h\left[Q_{(t)}^{\mathrm{vo}}\right]} \times 100$,

where $Q_{(t)}^{\mathrm{vo}}$ is the virtual-observed streamflow and $Q_{(t)}^{\mathrm{eval}}$ is the simulated streamflow from the selected virtual hydrological test (i.e. $Q^{\mathrm{sim}}$ if integrated test or $Q_{(k)}^{\mathrm{spl}}$ if unit test selected) in the evaluated time period $t$. This procedure is repeated for all replicates of the simulated streamflow such that a range of errors is reported for each test for the target time period.

Following the calculation of this error metric for all replicates of the integrated test and ensemble of unit tests $(k=$ $1, \ldots, 12)$, it is possible to investigate deficiencies in the simulated streamflow in terms of which influencing month(s) contribute more to the deficiencies in streamflow for the target time period based on that statistic of interest. Thus, for each site, statistic, and evaluated time period there are 13 sets of errors to compare.

A typical error profile from integrated and unit tests is shown in Fig. 4b where mean monthly flow is selected as the statistic of interest for the evaluated time period of June $(t=6)$. In this figure the sets of errors from the integrated and unit tests are summarised as boxplots with the boxplot whiskers indicating the $90 \%$ limits of the errors from the evaluated streamflow replicates. Figure $4 \mathrm{~b}$ shows the integrated test produced a median error of $27 \%$ (blue shaded boxplot) from all simulated rainfall replicates indicating a deficiency in the simulated streamflow for June. Examination of the unit tests (yellow and blue striped boxplots) for the target time period (June) shows that the median error is $20 \%$ when the influencing month is June $(k=6)$, the median error is $10 \%$ when the influencing month is May $(k=5)$ and when the influencing month is April $(k=4)$ the median error is negligible. Therefore, the bias in mean June streamflow is primarily due to SRM deficiencies in June and May respectively.

\subsubsection{Identify types of key deficiencies}

Following a side-by-side comparison of integrated test and unit test results in terms of the relative errors, the sources of poor performance should be classified in terms of in which influencing months streamflow deficiencies originate (e.g. poor streamflow arises from rainfall deficiencies mostly in the same month, a prior month, or a contiguous block of months). Differentiating between cases allows for SRM improvements to be targeted in terms of their ultimate impact on streamflow statistics. To complement this analysis a comparison of the virtual-observed flow duration curve for the evaluated time period with the flow duration curves resulting from 
unit tests for key influencing months is also recommended. Examples of each case are presented in Sect. 4.

\section{Case study}

The Onkaparinga catchment in South Australia is used as a case study (Fig. 5). The $323 \mathrm{~km}^{2}$ catchment lies $25 \mathrm{~km}$ south of the Adelaide metropolitan area and contains the largest reservoir in the Adelaide Hills supplying the region (Mount Bold Reservoir). The catchment has a strong seasonal cycle (shown in Fig. 6) where the driest months (December, January and February) exhibit low rainfall and low streamflow, the wettest months (July, August and September) have high rainfall and high streamflow, and the "wetting-up" period (April, May and June) has high rainfall and lower streamflow. There is a strong rainfall gradient (Fig. 5), with average annual rainfall ranging from approximately $500 \mathrm{~mm}$ on the coast (Site No. 19) to over $1000 \mathrm{~mm}$ in the region of highest elevations (Site No. 20). A breakdown of the rainfall characteristics (annual total, number of wet days, daily average amounts, wet-spell and dry-spell durations) at each site on a monthly basis is provided in the Supplement.

The evaluated daily rainfall was simulated using the latent variable autoregressive daily rainfall model of Bennett et al. (2018) using at-site calibrated parameters to simulate daily rainfall independently at each of the 22 sites. This rainfall model uses a latent variable concept, which relies on sampling from a normally distributed "hidden" variable. The latent variable can then be transformed to a rainfall amount by truncating values below zero and by rescaling values above zero to match the observed rainfall's distribution. Here, the rainfall is rescaled using a power transformation.

To calibrate the model the rainfall data at a given site is partitioned on a monthly basis and separate parameters are fit for each month. The mean and standard deviation of rainfall amounts, as well as the proportion of dry days is calculated. These statistics are matched to the corresponding properties of the truncated power transformed normal distribution. The at-site lag-1 temporal correlation is then calculated based on the observed wet-day periods for a given month. This statistic is transformed to the equivalent correlation of the underlying latent variable by accounting for the effects of truncation to determine the autocorrelation parameter. Full details of the calibration procedure are provided in Bennett et al. (2018). In this study the daily rainfall model was calibrated and simulated at 22 locations independently throughout the catchment that have long, high-quality records (Fig. 5). 10000 replicates of simulated rainfall covering a 73 year period (19141986) were used.

The hydrological model GR4J (Perrin et al., 2003) was used to simulate streamflow (both virtual-observed and simulated) at a daily time step. GR4J is a daily lumped hydrological model that simulates daily streamflow in a parsimonious manner using four parameters. The GR4J model was calibrated according to the procedure set out in Westra et al. (2014b) for the stationary version of the GR4J hydrological model. The details are provided in Westra et al. (2014a) and a short summary is provided here. The observed data from the multiple rainfall gauges in the Onkaparinga catchment were Thiessen weighted to calculate the catchment average rainfall, which was used purely for the purposes of calibrating the hydrological model. The hydrological model was calibrated to the daily streamflow data at Houlgrave Weir (see Fig. 5) using a model calibration period of 15 years (1985-1999). The model parameters were estimated using a maximum likelihood estimation procedure with a weighted least squares likelihood function. The set of hydrological model parameters that maximised the likelihood function were found using a multi-start quasi-Newton optimisation procedure with 100 random starts. Overall, the GR4J model was able to simulate streamflow with a good fit to the observed daily streamflow, with a Nash-Sutcliffe efficiency of 0.8. A similar type of hydrological model and calibration approach has been used for other virtual evaluation studies (Li et al., 2014, 2016). The same set of hydrological model parameters are used for both the unit and integrated tests so that the same transformation of rainfall to flow is used.

\section{Results}

\subsection{Step 1 - identify poor performing sites}

To undertake Step 1, annual total flow volumes were designated as the primary streamflow characteristic to narrow the number of sites investigated. Following the selection of the primary streamflow characteristic and selection of the hydrological model, GR4J, integrated tests were undertaken to evaluate the simulated rainfall at the 22 sites. The annual total flow distribution was used to give a broad indication of performance. This step categorised 10 of the 22 sites as "poor" and 12 as "good", which is in strong contrast to earlier evaluation efforts using observed-rainfall evaluation (Bennett et al., 2018) that categorised the majority of sites and statistics as "good" (see Sect. 2.2.3 for category definitions).

The 10 sites categorised as "poor" are the focus of subsequent virtual hydrological evaluation framework steps. These "poor" performing sites are indicated by the triangles in Fig. 5.

\subsection{Step 2 - identify poor performing time periods}

The poor performing sites identified in Step 1 were then compared in terms of both an observed-rainfall evaluation and virtual hydrological evaluation via an integrated test. Figure 7 graphically summarises this comparison, with each row presenting monthly or annual performance of the following statistics: 


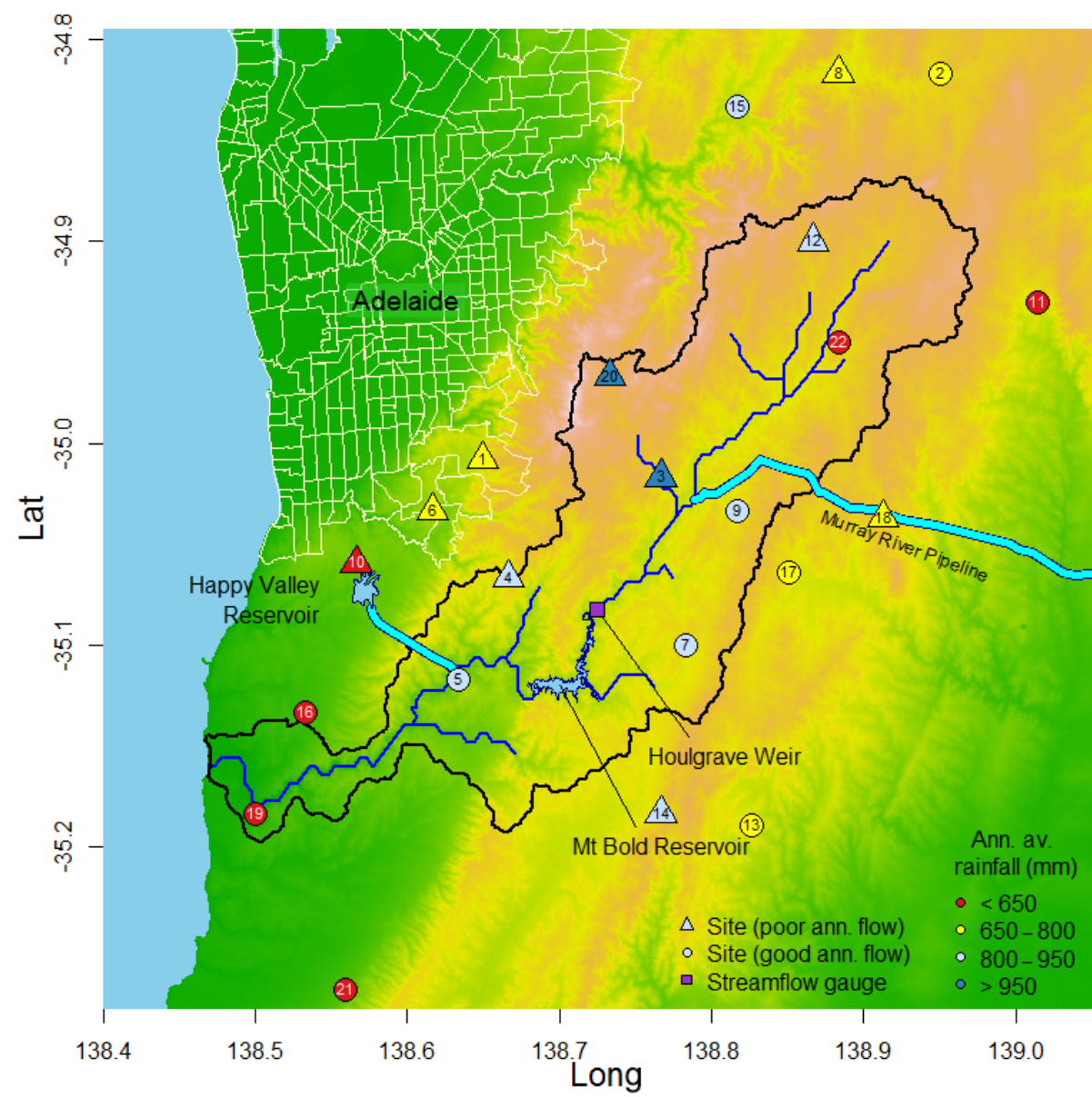

Figure 5. Onkaparinga catchment, South Australia. Sites indicated by triangles are explored in greater detail in this paper due to the relatively poorer ability of simulated rainfall to reproduce virtual-observed annual streamflow totals at these sites.

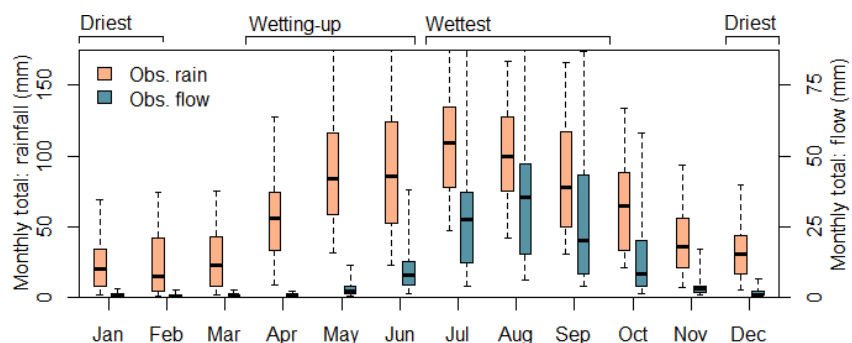

Figure 6. Seasonal variation of catchment average rainfall and flow at Houlgrave Weir. Boxplots show the variation across years. "Wettest" indicates months with higher rainfall and higher flow. "Driest" indicates months with lower rainfall and lower flow. "Wetting up" indicates months with higher rainfall and lower flow.

- simulated daily rainfall statistics (mean (m) daily amounts, standard deviation (SD) of daily amounts, mean number of wet days (nwet) and the standard deviation of the number of wet days);
- aggregate rainfall statistics (mean and standard deviation of total rainfall); and

- aggregate streamflow statistics (mean and standard deviation of total flow).

The first to fourth columns of Fig. 7 summarise the observedrainfall evaluation and the fifth and sixth of Fig. 7 summarise the virtual hydrological evaluation. The first column of Fig. 7 indicates that of the poor performing sites, the SRM exhibited "good" performance in simulating daily rainfall means and standard deviations as well as the mean number of wet days for all sites and months and at an annual level according to the observed-rainfall evaluation. Each of the three statistics presented in the first column are assessed separately but are presented together to avoid repetition. Whereas the second column indicates that there is mixed performance across sites and months in simulating the variability in the number of wet days ( $\mathrm{SD}(\mathrm{nwet}))$. Likewise, the third and fourth columns indicate overall "good" performance in simulating mean monthly totals and mixed performance in simulating the monthly or annual total standard deviations (SD(total)). 
(a) Observed-rainfall evaluation

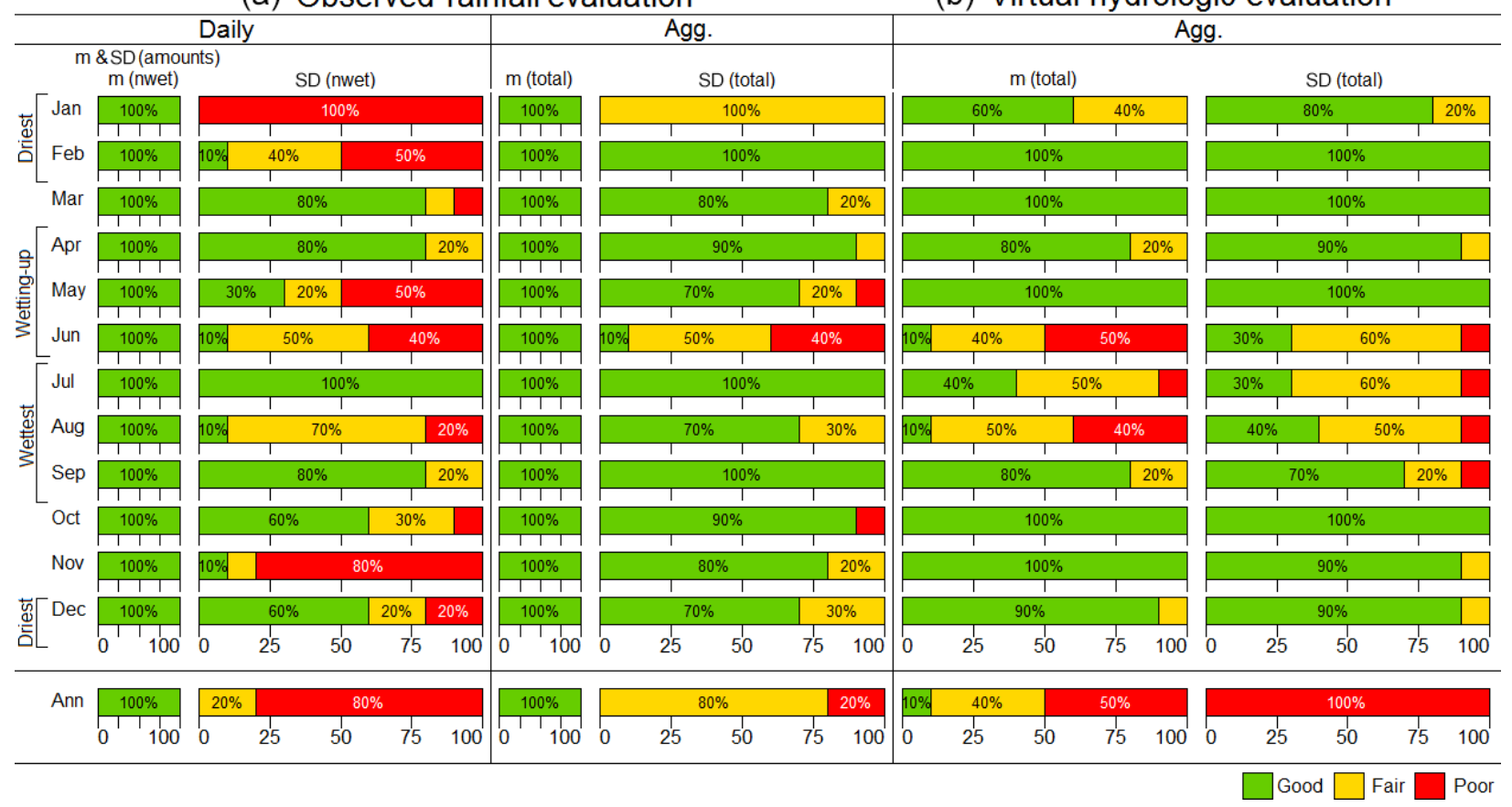

Figure 7. Integrated test, comparing observed-rainfall evaluation (a) with the virtual hydrologic evaluation (b). Comparison of daily and aggregate ("Agg.") rainfall statistics against aggregate flow statistics for individual months and years, where means are denoted as "m" and standard deviations as "SD".

Whereas the virtual hydrological evaluation (fifth and sixth) columns show mostly "good" performance in all months other than those in the "wettest" or "wetting-up" periods.

A clear trend from Fig. 7 is the contrast in performance between the observed-rainfall evaluation and the virtual hydrological evaluation. One contrast is that in the driest months (December, January, February) "poor" performance in simulating rainfall (based on observed-rainfall evaluation) did not necessarily translate to "poor" performance in simulating streamflow (based on virtual hydrological evaluation). For example, examining the first row of Fig. 7, the observedrainfall evaluation shows that in January the SRM's ability to simulate variability in the number of wet days, $\mathrm{SD}$ (nwet), was "poor" for all sites. However, in contrast the virtual hydrological evaluation shows that most sites had "good" performance in simulating the January distribution of monthly total flow (i.e. $\mathrm{m}$ (total) and $\mathrm{SD}($ total)).

A second contrast is that "good" performance in the observed-rainfall evaluation does not necessarily translate to "good" performance for the virtual hydrological evaluation, particularly for months in the "wettest" and "wetting-up" periods. For example, in Fig. 7 the rows summarising June and August show large percentages of "poor" sites in the virtual hydrological evaluation of monthly total flow. This deficiency would have been difficult to infer using the observedrainfall evaluation due to the $100 \%$ "good" performance of $\mathrm{m}$ (total) rainfall and "good/fair" performance of SD(total) rainfall in these months.

Likewise, by examining the bottom row of Fig. 7 that summarises annual performance, it can be seen that the observed-rainfall evaluation shows unbiased mean annual total, m(total), rainfall (100\% "good") and yet the mean annual total flows showed only $10 \%$ of sites as "good". Discussion of the unit tests in the following section will investigate reasons why apparently "good" rainfall can yield "poor" flow.

\subsection{Step 3 - identify sources of poor performance}

To undertake Step 3, unit tests were run to evaluate the source of deficiencies in poor performing time periods. The results of these test were compared against integrated tests in terms of their relative errors. From this comparison the source and type of key deficiencies in the simulated rainfall that lead to poor performance in simulated streamflow were identified. A comparison of the virtual-observed flow duration curve for the poor performing time periods and the flow duration curves resulting from unit tests for key influencing months was also undertaken to illustrate the impact of these key deficiencies on the daily flow duration curve.

Here, four examples of the different types of key deficiencies are illustrated using two locations, Site 12 and Site 10 (see Figs. 8 to 13). For completeness these results are presented together with the results of the observed-rainfall evaluation (panels a and b of Figs. 8 and 11). 

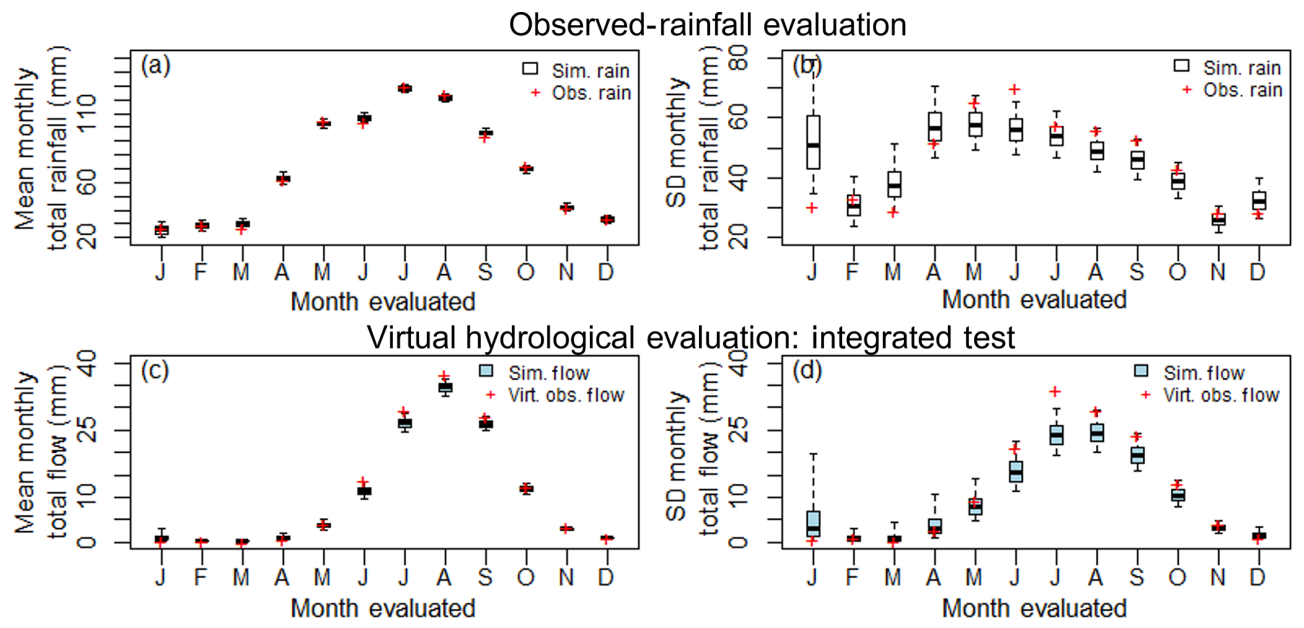

Figure 8. Lobethal, Site 12 (a) observed-rainfall evaluation mean monthly total rainfall, (b) observed-rainfall evaluation standard deviation of monthly total rainfall, (c) virtual hydrological evaluation (integrated test) mean monthly total streamflow, (d) virtual hydrological evaluation (integrated test) standard deviation of monthly total streamflow. Boxplot whiskers indicate the $90 \%$ limits of the simulated streamflow or rainfall replicates.

\subsubsection{Streamflow errors mostly originate from rainfall model deficiencies in the evaluated month}

A common case for streamflow errors is that they originate from rainfall in the same month. This case can be illustrated using Site 12 in Fig. 8 where left-side panels show results for the mean and right-side panels show the standard deviation and where panels (a) and (b) summarise the observed-rainfall evaluation, panels (c) and (d) summarise the integrated test. From panels (a) and (b), the simulated monthly rainfall is generally unbiased, but from panels (c) and (d) the mean and standard deviation of the simulated streamflow is lower than the virtual-observed flow from June to September. Here, September is selected as an illustrative case for an application of the unit test in Fig. 9 since it shows biased flow.

Taking September as the evaluated month $(t=9)$, Fig. 9a and $\mathrm{b}$ compare the unit tests for all 12 influencing months (yellow and blue striped boxplots) with the integrated test (blue shaded boxplot) in terms of the error in the simulated flow. When the influencing month is September (i.e. the September rainfall is "spliced" into the observed record, $k=9$ ) the resultant error is greatest and closest to the error for the integrated test for both the mean monthly total flow (Fig. 9a) and standard deviation of monthly total flow (Fig. 9c). For the example of the standard deviation, when the influencing month is July (i.e. July rainfall is spliced into the observed record) the median error is less than $2 \%$, whereas when September is taken as the influencing month the median error is approximately $16 \%$ (Fig. 9b). Therefore, to improve September flows, September rainfall should be improved in preference to all other months.

This need to improve September in preference to preceding months is also illustrated via Fig. 9c where the September daily flow duration curves are shown for the cases where $\mathrm{Au}$ - gust (orange shading) and September (blue shading) are the influencing months compared against the virtual-observed September flow duration curve (purple dots). Where August is selected as the influencing month, the virtual-observed flow duration curve largely sits inside the $90 \%$ limits of the flow duration curves resulting from the unit testing procedure. Whereas, the virtual-observed flow duration curve is located outside the $90 \%$ limits of the unit test flow duration curve when September is taken as the influencing month. Thereby providing further evidence that, to improve September flows, September rainfall should be improved in preference to other months.

Analysing other sites and months suggests that over $50 \%$ of the evaluations correspond to this case, and they typically occur in spring and summer months when the catchment is drying out.

\subsubsection{Streamflow errors originate from rainfall model deficiencies over a contiguous block of months}

An illustration of the case where streamflow errors originate from rainfall model deficiencies over a contiguous block of months is provided by Site 12, where July is selected as the evaluated month. Comparison of the July performance in the integrated and unit tests (Fig. 10a and b) demonstrates that the errors in July streamflow do not originate in the July rainfall alone (unlike the case for September - see Sect. 4.3.1). Although the largest percentage error in flow is attributable to July (a median error of $8 \%$ in mean monthly total flow and $25 \%$ in the standard deviation of monthly total flow when the influencing month is July) a significant proportion of the error for July streamflow originates in prior months. June and May rainfall have a significant influence on the July flow with percentage errors of up to $15 \%$ in July flow when June or 


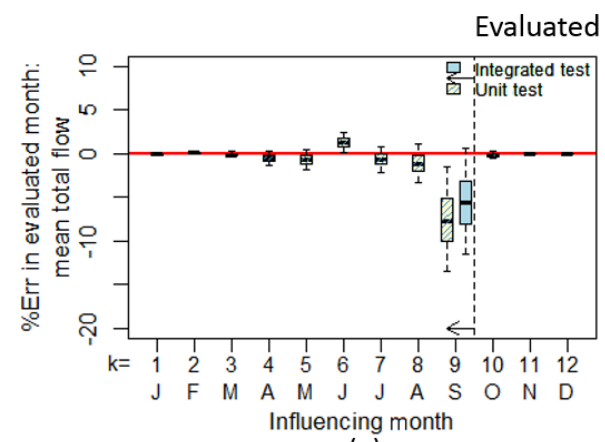

(a)

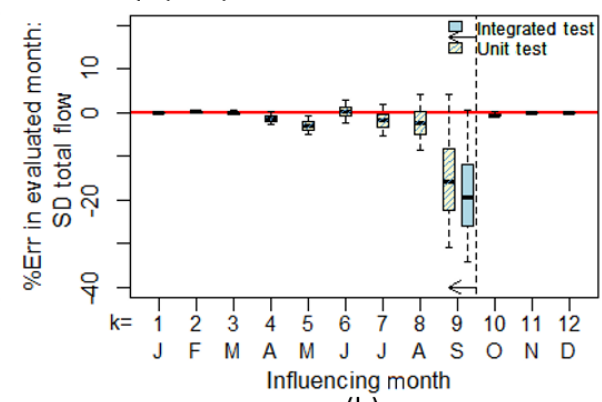

(b)

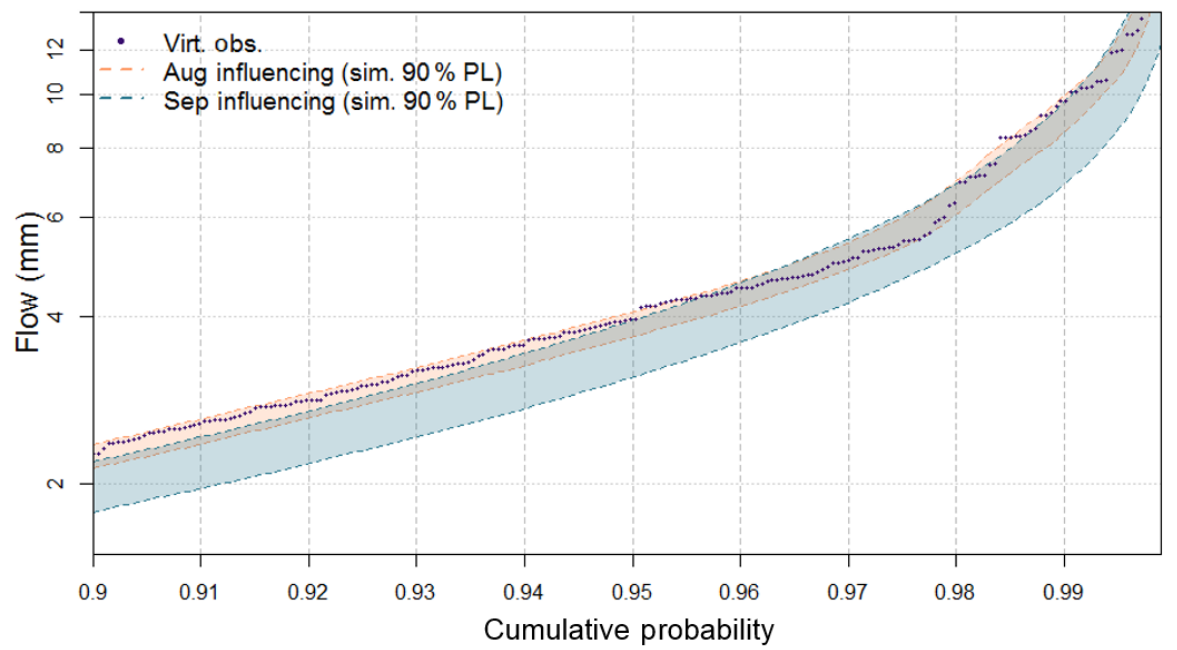

(c)

Figure 9. Lobethal, Site 12 (a) unit test error in mean monthly flow (September), (b) unit test error in standard deviation of monthly flow (September), (c) unit test September flow duration curve when August and September are selected as influencing months (top $10 \%$ of flow days shown). Boxplot whiskers indicate the $90 \%$ limits of the simulated streamflow replicates.

May are the influencing month. Therefore, to improve July flows, it is not just the July rainfall that should be improved, but also the preceding 2 months.

This need to improve July and preceding months is also illustrated via Fig. 10c where the July daily flow duration curves are shown for the cases where June (orange shading) and July (blue shading) are the influencing months compared against the virtual-observed July flow duration curve (purple dots). For both cases the virtual-observed flow duration curve is located outside the $90 \%$ limits of the flow duration curves resulting from the unit testing procedure.

Typically, "wetting-up" and "wettest" months fall in this case where streamflow errors originate from rainfall model deficiencies over a contiguous block of months, approximately $40 \%$ of the site/month combinations.

\subsubsection{Streamflow errors originate from rainfall model deficiencies in a preceding month more so than evaluated month}

An example of the case where the largest contribution to streamflow errors arises from rainfall deficiencies in a pre- ceding month is provided by Site 10 , where July is selected as the evaluated month. July is selected as an illustrative case for application of the unit test since it shows biased flow (see Fig. 11c and d), but did not show any bias in the simulated rainfall (see Fig. 11a and b).

The largest contributor to error in July flow is not July rainfall but June rainfall (Fig. 12a and b). That is, the largest errors occur when there is observed rainfall for July spliced with simulated rainfall for June. In contrast, simulated July rainfall spliced with observed rainfall in other months yields a smaller median error. This deficiency in June rainfall can also be seen in an examination of the July flow duration curves (Fig. 12c) where the virtual-observed flow duration curve sits within the $90 \%$ limits of the simulated flow duration curve where July is designated as the influencing month, whereas when June is designated as the influencing month the virtual-observed flow duration curve sits outside the $90 \%$ limits for a number of the higher flow days.

While improving the July rainfall will improve the simulation of July flow, a more significant improvement will be obtained by focusing on improving the June rainfall. The category where streamflow errors originate from rainfall model 
Evaluated month July $(t=7)$

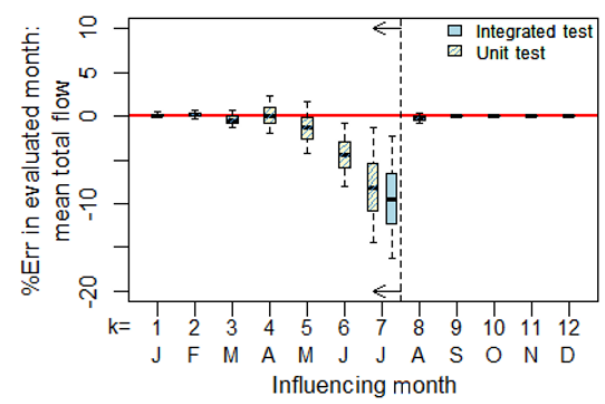

(a)

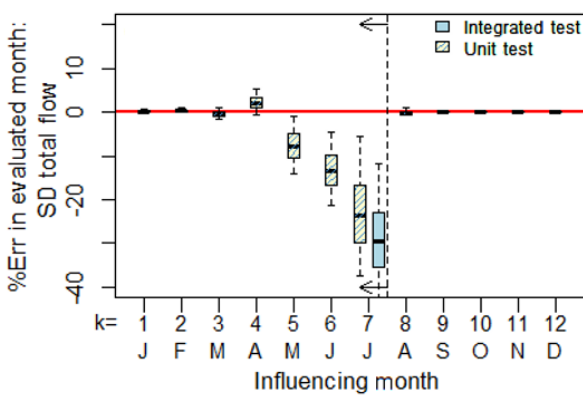

(b)

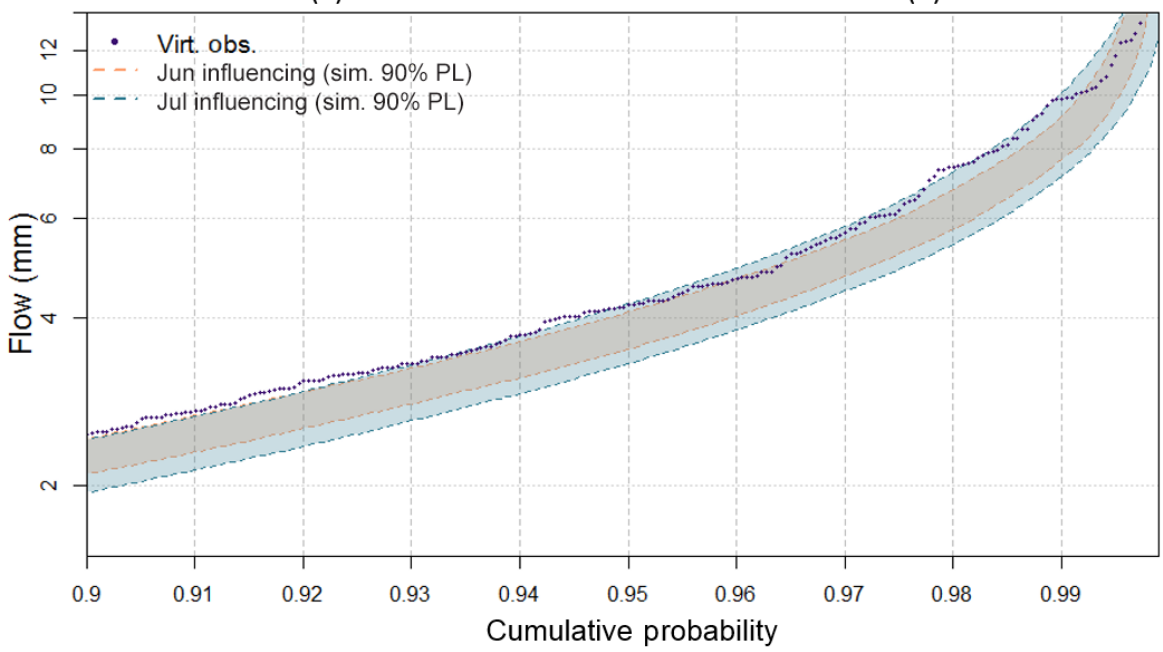

(c)

Figure 10. Lobethal, Site 12 (a) unit test error in mean monthly total flow (July), and (b) unit test error in standard deviation of monthly total flow (July), (c) July flow duration curve when June and July are selected as influencing months in unit test (top $10 \%$ of flow days shown). Boxplot whiskers indicate the $90 \%$ limits of the simulated streamflow replicates.

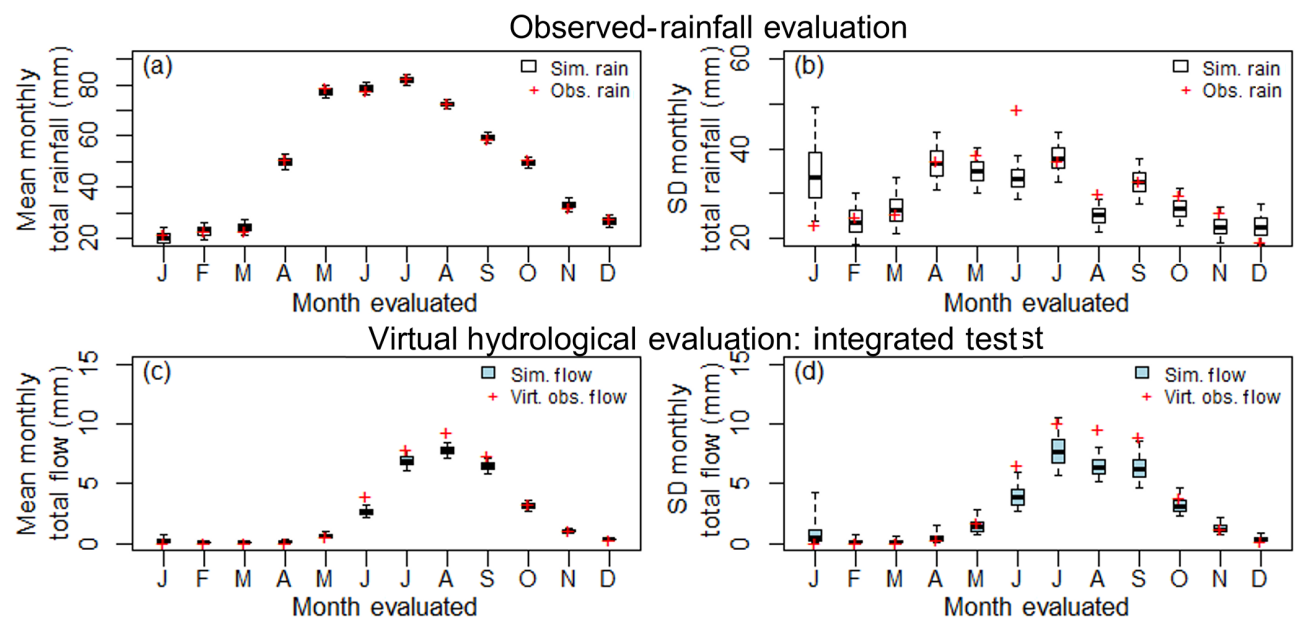

Figure 11. Happy Valley, Site 10 (a) observed-rainfall evaluation mean monthly total rainfall, (b) observed-rainfall evaluation standard deviation of monthly total rainfall, (c) virtual hydrological evaluation (integrated test) mean monthly total streamflow (d) virtual hydrological evaluation (integrated test) standard deviation of monthly total streamflow. Boxplot whiskers indicate the $90 \%$ limits of the simulated streamflow or rainfall replicates. 
Evaluated month July $(t=7)$

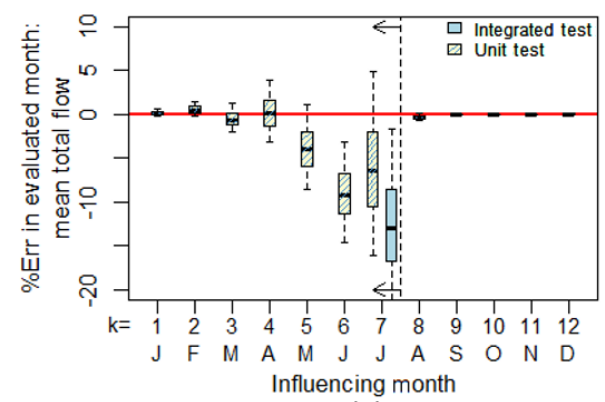

(a)

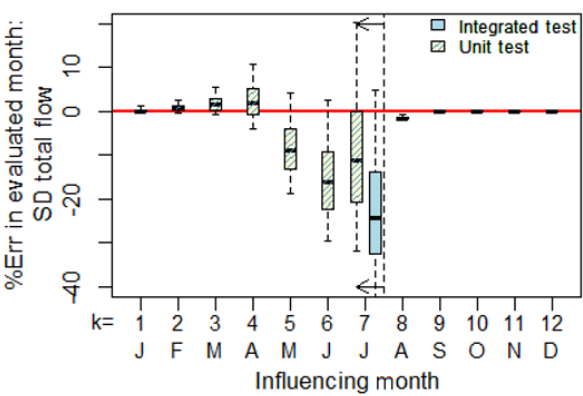

(b)

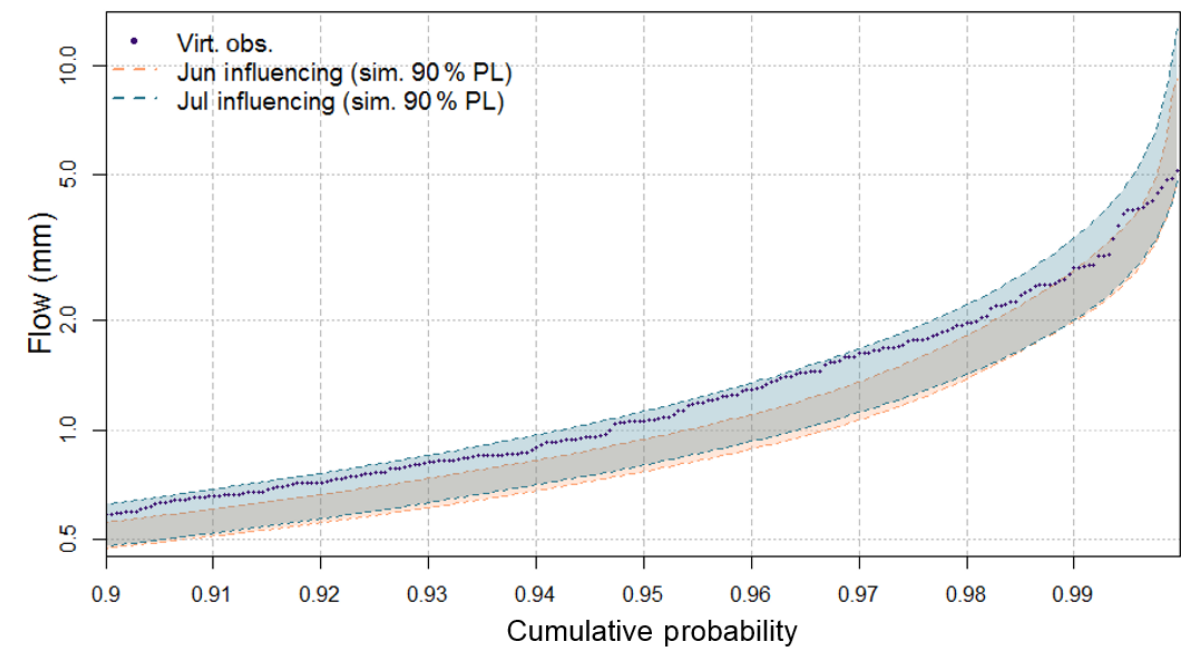

(c)

Figure 12. Happy Valley, Site 10 (a) unit test error in mean monthly flow (July), (b) unit test error in standard deviation of monthly flow (July), and (c) July flow duration curve when June and July are selected as influencing months in the unit test (top $10 \%$ of flow days shown). Boxplot whiskers indicate the $90 \%$ limits of the simulated streamflow replicates.

deficiencies in a preceding month represents about $10 \%$ of the evaluated site/month combinations (i.e. those identified in Step 2).

\subsubsection{Influence of monthly rainfall on annual flow volumes}

While annual simulated rainfall was unbiased, annual simulated streamflow was biased. An illustration of how errors in annual total streamflow arise from deficiencies in simulated rainfall is shown for Site 10. Figure 13a and b show that when the months of May to August are assessed as the influencing month they produce the largest errors in distribution of annual total flow for Site 10. Splices of other months do not significantly degrade the simulation of total annual flow. This deficiency can also be seen via an examination of the flow duration curve (Fig. 13c) in which the virtual-observed flow duration curve is located outside portions of the simulated flow duration curves where May or June are designated as the influencing month. Improvements to the simulation of annual total flow will therefore come from improving the SRM in the "wetting-up" and wettest months of the seasonal cycle
(May to August). This insight from the use of unit testing would be difficult to obtain using other evaluation strategies (further discussed in Sect. 5.2).

\section{Discussion}

\subsection{The importance of streamflow-based evaluation}

Streamflow arises from the integration of rainfall processes (e.g. rainfall amounts, occurrences and wet-dry patterns) over a catchment. Features of the catchment, such as catchment storage, thresholds and nonlinearities in the rainfallstreamflow response function, can either act to amplify or dampen the rainfall errors at different times of the year. These behaviours were clearly identified and demonstrated in Step 2 of the virtual hydrological evaluation framework that compares observed-rainfall evaluation and virtual hydrological evaluation (see Sect. 4.2).

In terms of amplification, the elasticity of the rainfallstreamflow response (Chiew, 2006) suggests that catchments can have strong sensitivities to discrepancies in rainfall. 
Evaluated period annual

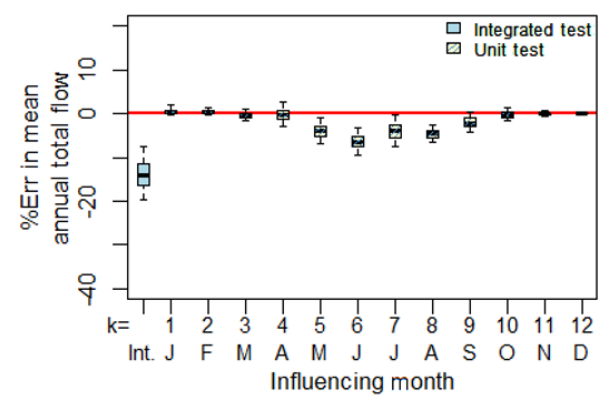

(a)

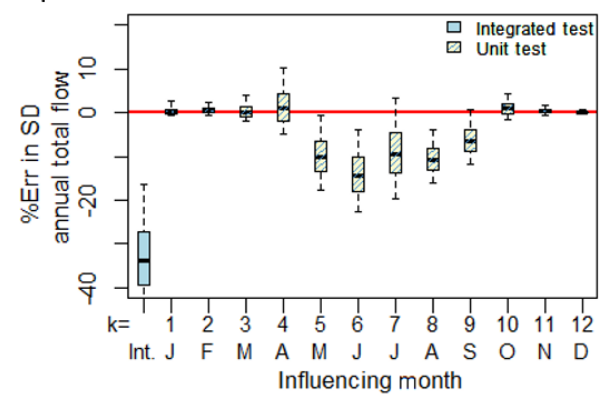

(b)

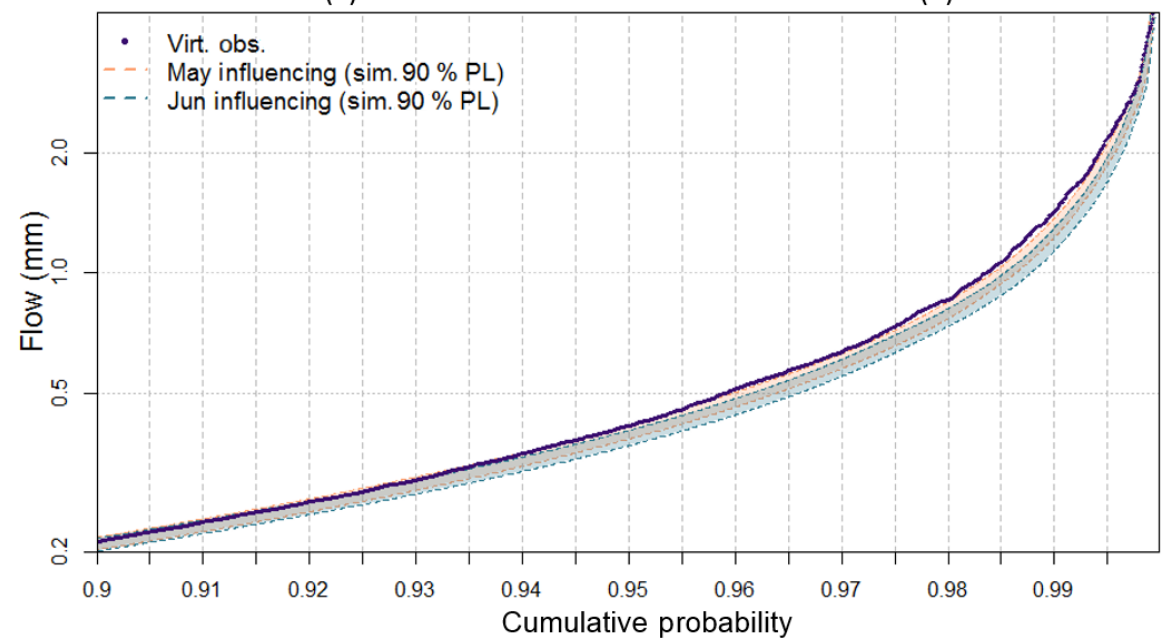

(c)

Figure 13. Happy Valley, Site 10 (a) unit test error in mean annual total flow, and (b) unit test error in standard deviation of annual total flow, and (c) annual flow duration curve when May and June are selected as influencing months in unit test (top $10 \%$ of flow days shown). Boxplot whiskers indicate the $90 \%$ limits of the simulated streamflow replicates.

Given that the rainfall elasticity of streamflow to rainfall is a factor of 2 to 3.5 (Chiew, 2006), using the principles of error propagation (Ang and Tang, 2007), assuming linearity it follows that a $10 \%$ error in mean/standard deviation of rainfall could potentially be amplified to $20 \%-35 \%$ error in the mean/standard of streamflow. This estimate represents a lower-bound of the potential amplification, since the nonlinear nature of the rainfall-runoff transformation will likely produce a larger potential amplification of errors. This indicates that streamflow-based evaluation of rainfall models provides a stronger test than observed-rainfall evaluation in terms of the sensitivity of the statistics. For example, Fig. 7 shows that July rainfall statistics were classified as "good", yet despite this, the streamflow response was "poor" (see Sect. 4.2 for further discussion). It could be argued that the rainfall results presented in Fig. 7 were classified as "good" because the observed-rainfall evaluation was limited, but the evaluation was methodical and used a comprehensive range of daily and monthly statistics (Bennett et al., 2018). While many rainfall statistics were preserved (means, standard deviation, extremes, marginal distributions of daily rainfall) the rainfall-streamflow response of the catchment exposes that there are deficiencies in the rainfall model not clearly identified by the observed-rainfall evaluation (Bennett et al., 2018).

In terms of dampened influence, catchment storages and high evapotranspiration can also act to suppress errors in the rainfall simulations. For example, Fig. 7 showed that the variability in the number of wet days, $\mathrm{SD}$ (nwet), was "poor" for all sites in January, yet this did not result in "poor" streamflow. The high potential evapotranspiration in January indicates that the majority of rainfall in January is converted into actual evapotranspiration yielding little streamflow. Hence, any errors in rainfall do not noticeably impact on January streamflow.

It is clear that streamflow-based evaluation is beneficial in addition to conventional observed-rainfall evaluation.

\subsection{The benefits of the virtual evaluation framework}

A benefit of virtual hydrological evaluation is that it is a relative measure of performance, where the hydrological model is a common factor in the construction of virtual-observed and simulated streamflow. This enables discrepancies in the streamflow to be identified in terms of SRM features. In con- 
trast, observed-streamflow evaluation is typically hampered by difficulties in separating the impact of data errors, hydrological model predictive performance from the errors in the SRM. A further benefit is the ability to undertake streamflowbased evaluation at any site where rainfall is observed and simulated. This enables insights into the SRM performance for simulating streamflow on a site-by-site basis.

The use of a virtual hydrological framework for evaluation provides the unique opportunity to develop innovative tests that can target specific aspects of the SRM. This paper introduces an innovative unit test that was used as a method for isolating the influence of rainfall in a month (i.e. the influencing month) on streamflow in an evaluated month while excluding the possibility of deficiencies from other rainfall months. The test enables a procedure for targeting months that are influential in terms of streamflow production rather than interpreting model performance based on blunt evaluation of rainfall or streamflow.

This unit test provides added value over and above the integrated test because it identifies which are the influencing months that have deficiencies in the modelled rainfall that produce poor streamflow predictions. For example, Sect. 4.3.2 illustrated that while the integrated test identified that there was poor streamflow in July for Site 12, the unit test was able to identify that the simulated rainfall in the prior influencing months of both May and June (Fig. 10) made significant contributions (10\%-15\% errors) to July's poor streamflow. A second example is shown in the influence of monthly rainfall on the errors in annual flow volumes in Sect. 4.3.4. If the modeller had focussed on improving the SRM by focusing on months with the highest contribution to annual total flow, July to September would have been identified as important, whereas the unit test identifies a different focus (May-August). The unit tests in Sect. 4.3.4 show that May and June combined make up $13 \%$ of the total annual flow volume (Fig. 11c). However, they contribute to $11 \%$ of the error in the mean annual total flow (Fig. 13a) and $24 \%$ error in the standard deviation (Fig. 13b). By contrast, September is a high-flow month contributing $21 \%$ of the annual total flow, but only $2 \%$ error in the mean and $6 \%$ error in the standard deviation. Without the unit test, it would have been less clear that the "wetting-up" months such as May and June were a more important focus for SRM improvement than a high-flow month such as September.

\subsection{Identifying key deficiencies in the rainfall properties of the SRM}

The previous section highlighted that simulated rainfall in the "wetting-up" period May-June was a key cause of errors in the streamflow. Returning to the observed-rainfall evaluation of the SRM (see Fig. 7) enables identification of the rainfall properties that are likely to be the cause of these errors in the streamflow. In the May-June months, the mean and standard deviation of rainfall amounts on wet days and the mean num- ber of wet days show $100 \%$ "good" performance, while the standard deviation of the number of wet days shows a high proportion of sites with "poor" performance $(50 \%$ of sites in May and $40 \%$ of sites in June). This identifies that rainfall amounts on wet days are reproduced well, but there is not enough variability in the rainfall occurrences in the key months of May-June. The observed-rainfall evaluation identifies that this is a common problem for this SRM, with 8 months having some proportion of "poor" sites for the standard deviation of the number of wet days - similar results were found in Bennett et al. (2018). However, the virtual hydrological evaluation identified that it is the rainfall occurrences in 2 key months (May and June) that will provide the most benefit in terms of virtual hydrological evaluation. This provides clear guidance on the rainfall properties that need to be improved for this SRM.

\subsection{Limitations and future research}

The virtual hydrological framework for SRM evaluation provides an opportunity for further improvements in the future to substantially augment the framework's diagnostic capabilities, including the following.

i. Using multiple, well-tested hydrological models - a potential limitation of the virtual hydrologic evaluation framework is that it is reliant on the use of a single hydrological model. Hydrological model structural errors may potentially skew interpretation of the SRM evaluation if the hydrological model poorly represents the catchment processes. To reduce these impacts the steps taken in this study included (a) using a well-tested hydrological model that has demonstrated good performance on a wide range of catchments (e.g. the GR4J model has been widely tested - see Perrin et al., 2003 and Coron et al., 2012); and (b) calibrating and evaluating the hydrological model on a catchment close to the observed rainfall sites to ensure it provided sufficiently good performance (e.g. GR4J was calibrated to the Onkaparinga catchment - see Westra et al., 2014b, a). Future research will use multiple, well-tested hydrological models with sufficiently good performance to reduce the reliance on a single hydrological model and to ensure the identification of SRM deficiencies is not dependent on a single hydrological model.

ii. Comparison of SRMs - this framework can be extended to provide more direct guidance on which rainfall features (in terms of components of the SRM) should be modified to improve streamflow performance. This can be done by comparing multiple rainfall model variants (parametrically, or via bootstrap techniques) which are designed to have contrasting features of a key characteristic (e.g. intermittency, rainfall correlation). Such an approach was undertaken by Evin et al. (2018) using an observed-rainfall evaluation approach. If the SRMs 
have monthly/seasonal autocorrelation (these were not significant for the rainfall in the Onkaparinga catchment), the unit testing approach would need to be extended by conditionally sampling the simulated rainfall in a manner that preserves monthly correlations.

iii. Evaluation of temporal non-stationarity - this framework can be extended to evaluate the impact of nonstationarity on SRM model performance by applying it on a selected non-stationary period. Care would be needed in the selection of statistics to identify model performance (since the performance in different subperiods could be masked when evaluating an overall period). A related issue is that the hydrological model should provide adequate performance across the range of non-stationary climate forcings to which it is subjected.

iv. Evaluation of spatial performance - there are multiple opportunities to develop tests for spatial performance, including (a) repeating the integrated test for all sites, and for catchment average rainfall means it would be possible to diagnose whether specific locations or the spatial dependence cause poor reproduction of streamflow statistics; (b) developing a spatial unit test (which is analogous to the temporal unit test but extended to space) where different combinations of sites are "spliced" in the construction of catchment average rainfall - to evaluate the impact of "mixed" performance in the SRMs between sites on the catchment average rainfall; and (c) these spatial unit tests could be used to evaluate stochastic weather generators more generally as well as spatially distributed rainfall generators - though these would require a spatially distributed hydrological model.

v. Evaluation of SRMs at subdaily timescales - this extension to evaluate SRMs at other timescales provides opportunities for the development of further unit test variants that focus on a range of different aspects of subdaily rainfall (intensity, duration, persistence) and its impact on streamflow characteristics of interest (e.g. subdaily flow peaks). This extension would require the use of a well-tested continuous subdaily hydrological model capable of simulating the relevant streamflow characteristics.

\section{Conclusions}

This paper has introduced a virtual hydrologic evaluation framework that enables targeted hydrological evaluation of SRMs. The framework formalises virtual streamflow investigations by (1) using a comprehensive and systematic evaluation approach to evaluate performance and (2) introducing two key innovations, an integrated test and a unit test. The integrated test compares simulated streamflow and virtualobserved streamflow to detect overall deficiencies in the ability of at-site simulated rainfall to reproduce streamflow statistics. The unit test enables the attribution of detected streamflow errors to specific months of simulated rainfall. The integrated and unit tests enabled different conclusions to be reached in terms of priorities for improving the SRM. These conclusions would not otherwise have been possible with conventional evaluation methods that focus either on rainfall statistics or on high-streamflow months. The integrated test demonstrated that while large discrepancies were identified in low rainfall months, these did not translate to deficiencies in streamflow due to the dry state of the catchment. The test also indicated instances where simulated rainfall categorised as "good" translated to "poor" flow due to the influence of catchment "memory" and rainfall from prior months. The unit test identified the importance of the simulated rainfall in the transition months of May and June (late autumn/early winter) during the "wetting-up" phase of the catchment cycle for producing low errors in subsequent highstreamflow months (July/August/September) and the annual streamflow distribution. The virtual hydrological evaluation framework provides valuable additional diagnostic ability for the development and application of SRMs not available by using rainfall-based evaluation techniques alone.

Data availability. All the data used in this study can be requested by contacting the corresponding author Bree Bennett at bree.bennett@adelaide.edu.au.

Supplement. The supplement related to this article is available online at: https://doi.org/10.5194/hess-23-4783-2019-supplement.

Author contributions. BBe conceived and executed the analysis, with input from MT, MLe, MLa, and BBa. MT, MLe, MLa, and $\mathrm{BBa}$ contributed to assisting with method development, interpretation, and analysis. BBe, MT, and MLe mostly wrote, reviewed, and revised the paper.

Competing interests. The authors declare that they have no conflict of interest.

Acknowledgements. This work was supported by an Australian Research Council Discovery grant with additional support provided by the CSIRO Climate Adaptation Flagship. We thank Hannes Müller-Thomy and two anonymous reviewers for their constructive comments and feedback that helped substantially improve the manuscript. 
Financial support. This research has been supported by the Australian Research Council (grant no. DP1094796).

Review statement. This paper was edited by Nadav Peleg and reviewed by Hannes Müller-Thomy and two anonymous referees.

\section{References}

Andreassian, V., Perrin, C., Michel, C., Usart-Sanchez, I., and Lavabre, J.: Impact of imperfect rainfall knowledge on the efficiency and the parameters of watershed models, J. Hydrol., 250, 206-223, 2001.

Ang, A. and Tang, W.: Probability Concepts in Engineering: Emphasis on Applications to Civil and Environmental Engineering (2nd Edition), John Wiley \& Sons Inc, Hoboken, New Jersey, USA, ISBN 10 0-471-72064-X, 2007.

Ball, J. E.: The influence of storm temporal patterns on catchment response, J. Hydrol., 158, 285-303, 1994.

Baxevani, A. and Lennartsson, J.: A spatiotemporal precipitation generator based on a censored latent Gaussian field, Water Resour. Res., 51, 4338-4358, https://doi.org/10.1002/2014WR016455, 2015.

Bennett, B., Thyer, M., Leonard, M., Lambert, M., and Bates, B.: A comprehensive and systematic evaluation framework for a parsimonious daily rainfall field model, J. Hydrol., 556, 1123-1138, 2018.

Blazkova, S. and Beven, K.: Flood frequency estimation by continuous simulation for a catchment treated as ungauged (with uncertainty), Water Resour. Res., 38, 14-11-14-14, 2002.

Blazkova, S. and Beven, K.: A limits of acceptability approach to model evaluation and uncertainty estimation in flood frequency estimation by continuous simulation: Skalka catchment, Czech Republic, Water Resour. Res., 45, W00B16, https://doi.org/10.1029/2007WR006726, 2009.

Camici, S., Tarpanelli, A., Brocca, L., Melone, F., and Moramarco, T.: Design soil moisture estimation by comparing continuous and storm-based rainfall-runoff modeling, Water Resour. Res., 47, W05527, https://doi.org/10.1029/2010WR009298, 2011.

Chiew, F. H.: Estimation of rainfall elasticity of streamflow in Australia, Hydrolog. Sci. J., 51, 613-625, 2006.

Coron, L., Andreassian, V., Perrin, C., Lerat, J., Vaze, J., Bourqui, M., and Hendrickx, F.: Crash testing hydrological models in contrasted climate conditions: An experiment on 216 Australian catchments, Water Resour. Res., 48, W05552, https://doi.org/10.1029/2011WR011721, 2012.

Coxon, G., Freer, J., Westerberg, I., Wagener, T., Woods, R., and Smith, P.: A novel framework for discharge uncertainty quantification applied to 500 UK gauging stations, Water Resour. Res., 51, 5531-5546, 2015.

Evin, G., Thyer, M., Kavetski, D., McInerney, D., and Kuczera, G.: Comparison of joint versus postprocessor approaches for hydrological uncertainty estimation accounting for error autocorrelation and heteroscedasticity, Water Resour. Res., 50, 2350-2375, 2014.

Evin, G., Favre, A.-C., and Hingray, B.: Stochastic generation of multi-site daily precipitation focusing on extreme events, Hy- drol. Earth Syst. Sci., 22, 655-672, https://doi.org/10.5194/hess22-655-2018, 2018.

Henley, B. J., Thyer, M. A., and Kuczera, G.: Climate driver informed short-term drought risk evaluation, Water Resour. Res., 49, 2317-2326, 2013.

Khedhaouiria, D., Mailhot, A., and Favre, A.-C.: Daily Precipitation Fields Modeling across the Great Lakes Region (Canada) by Using the CFSR Reanalysis, J. Appl. Meteorol. Clim., 57, 24192438, 2018.

Kim, D. and Olivera, F.: Relative importance of the different rainfall statistics in the calibration of stochastic rainfall generation models, J. Hydrol. Eng., 17, 368-376, 2011.

Kuczera, G. and Williams, B. J.: Effect of rainfall errors on accuracy of design flood estimates, Water Resour. Res., 28, 1145-1154, 1992.

Li, J., Thyer, M., Lambert, M., Kuczera, G., and Metcalfe, A.: An efficient causative event-based approach for deriving the annual flood frequency distribution, J. Hydrol., 510, 412-423, 2014.

Li, J., Thyer, M., Lambert, M., Kuzera, G., and Metcalfe, A.: Incorporating seasonality into event-based joint probability methods for predicting flood frequency: A hybrid causative event approach, J. Hydrol., 533, 40-52, 2016.

McInerney, D., Thyer, M., Kavetski, D., Lerat, J., and Kuczera, G.: Improving probabilistic prediction of daily streamflow by identifying Pareto optimal approaches for modeling heteroscedastic residual errors, Water Resour. Res., 53, 2199-2239, 2017.

McMillan, H. K. and Brasington, J.: End-to-end flood risk assessment: A coupled model cascade with uncertainty estimation, Water Resour. Res., 44, W03419, https://doi.org/10.1029/2007WR005995, 2008.

Mortazavi-Naeini, M., Kuczera, G., Kiem, A. S., Cui, L., Henley, B., Berghout, B., and Turner, E.: Robust optimization to secure urban bulk water supply against extreme drought and uncertain climate change, Environ. Modell. Softw., 69, 437-451, 2015.

Müller, H. and Haberlandt, U.: Temporal rainfall disaggregation using a multiplicative cascade model for spatial application in urban hydrology, J. Hydrol., 556, 847-864, 2018.

Nicótina, L., Alessi Celegon, E., Rinaldo, A., and Marani, M.: On the impact of rainfall patterns on the hydrologic response, Water Resour. Res., 44, W12401, https://doi.org/10.1029/2007WR006654, 2008.

Paschalis, A., Molnar, P., Fatichi, S., and Burlando, P.: A stochastic model for high-resolution space-time precipitation simulation, Water Resour. Res., 49, 8400-8417, 2013.

Paton, F. L., Maier, H. R., and Dandy, G. C.: Relative magnitudes of sources of uncertainty in assessing climate change impacts on water supply security for the southern Adelaide water supply system, Water Resour. Res., 49, 1643-1667, 2013.

Perrin, C., Michel, C., and Andréassian, V.: Improvement of a parsimonious model for streamflow simulation, J. Hydrol., 279, 275289, 2003.

Rasmussen, P.: Multisite precipitation generation using a latent autoregressive model, Water Resour. Res., 49, 1845-1857, 2013.

Renard, B., Kavetski, D., Leblois, E., Thyer, M., Kuczera, G., and Franks, S. W.: Toward a reliable decomposition of predictive uncertainty in hydrological modeling: Characterizing rainfall errors using conditional simulation, Water Resour. Res., 47, W11516, https://doi.org/10.1029/2011WR010643, 2011. 
Shah, S. M. S., O'Connell, P. E., and Hosking, J. R. M.: Modelling the effects of spatial variability in rainfall on catchment response. 2. Experiments with distributed and lumped models, J. Hydrol., 175, 89-111, 1996.

Sikorska, A. E., Viviroli, D., and Seibert, J.: Effective precipitation duration for runoff peaks based on catchment modelling, J. Hydrol., 556, 510-522, 2018.

Srikanthan, R. and Pegram, G. G. S.: A nested multisite daily rainfall stochastic generation model, J. Hydrol., 371, 142-153, 2009.

Westra, S., Thyer, M., Leonard, M., Kavetski, D., and Lambert, M.: Impacts of climate change on surface water in the Onkaparinga catchment - volume 1: hydrological model development and sources of uncertainty, Goyder Institute for Water Research Technical Report Series No. 14/22, Adelaide, South Australia, 1839-2725, 2014a.
Westra, S., Thyer, M., Leonard, M., Kavetski, D., and Lambert, M.: A strategy for diagnosing and interpreting hydrological model nonstationarity, Water Resour. Res., 50, 5090-5113, 2014 b.

Wilks, D. S.: High-resolution spatial interpolation of weather generator parameters using local weighted regressions, Agr. Forest Meteorol., 148, 111-120, 2008.

Wilson, C. B., Valdes, J. B., and Rodriguez-Iturbe, I.: On the influence of the spatial distribution of rainfall on storm runoff, Water Resour. Res., 15, 321-328, 1979. 